\title{
Article \\ Seasonal Trends of Viral Prevalence and Incidence of Kawasaki Disease: A Korea Public Health Data Analysis
}

\author{
Jae Hee Lim ${ }^{1,+}$, Yu Kyeong Kim ${ }^{1,+}$, So Hyeon Min ${ }^{1,+}$, Sang Won Kim ${ }^{2}{ }^{\oplus}$, Young Hwan Lee ${ }^{3, *}$ \\ and Jae Min Lee ${ }^{3, *(\mathbb{D}}$ \\ 1 Department of Medicine, College of Medicine, Yeungnam University, Daegu 42415, Korea; \\ imjh520@naver.com (J.H.L.); dbrud21206@naver.com (Y.K.K.); 3000min@naver.com (S.H.M.) \\ 2 Medical Research Center, College of Medicine, Yeungnam University, Daegu 42415, Korea; \\ kimsw3767@ynu.ac.kr \\ 3 Department of Pediatrics, College of Medicine, Yeungnam University, Daegu 42415, Korea \\ * $\quad$ Correspondence: yhlee@med.yu.ac.kr (Y.H.L.); mopic@yu.ac.kr (J.M.L.); Tel.: +82-53-640-6999 (Y.H.L.); \\ +82-53-620-3536 (J.M.L.) \\ + These authors contributed equally to this study.
}

Citation: Lim, J.H.; Kim, Y.K.; Min, S.H.; Kim, S.W.; Lee, Y.H.; Lee, J.M. Seasonal Trends of Viral Prevalence and Incidence of Kawasaki Disease: A Korea Public Health Data Analysis. J. Clin. Med. 2021, 10, 3301. https:// doi.org/10.3390/jcm10153301

Academic Editors: Ryuji Fukazawa and Reinhard Kopp

Received: 24 May 2021

Accepted: 22 July 2021

Published: 27 July 2021

Publisher's Note: MDPI stays neutral with regard to jurisdictional claims in published maps and institutional affiliations.

Copyright: (c) 2021 by the authors. Licensee MDPI, Basel, Switzerland. This article is an open access article distributed under the terms and conditions of the Creative Commons Attribution (CC BY) license (https:// creativecommons.org/licenses/by/ $4.0 /)$.

\begin{abstract}
Kawasaki disease (KD) is a systemic vasculitis that occurs mainly in children under 5 years of age and is often accompanied by coronary artery lesions. The cause of the disease remains undetermined, but it is estimated to result from viral or bacterial infections. Certain studies have shown infection as a leading cause of KD. The purpose of this study was to investigate the relationship between KD incidence and viral infections in different pediatric age groups, using the Health Insurance Review and Assessment (HIRA) Open Access Big Data Platform, to confirm seasonal trends by analyzing monthly patterns. We investigated the HIRA data of KD patients (M30.3) who were treated with intravenous immunoglobulin from 2015 to 2018. Weekly virus positive detection rate data (PDR) for this period was obtained from the Korea Disease Control and Prevention Agency for human adenovirus (HAdV), human parainfluenza virus (HPIV), human respiratory syncytial virus (HRSV), influenza virus (IFV), human coronavirus (HCoV), human rhinovirus (HRV), human bocavirus (HBoV), human metapneumovirus (HMPV), rotavirus, norovirus, and astrovirus. We then analyzed the weekly/monthly virus PDR and its association with KD incidence, including monthly incidence patterns, and seasonal trends. Seasonal trend analysis of the virus PDR was performed using the time series analysis method through ARIMA (Autoregressive Integrated Moving Average). Correlations between KD incidence and PDR at 1- and 2-month intervals were analyzed using the Granger test. A total of 16,740 patients were diagnosed with KD during the study period, mainly young children, with a male-to-female ratio of 1.35 . Specifically, 15,635 (93\%) patients were under 5 years of age, with an incidence rate of 172.4/100,000 person-years. Annually, the cumulative number of cases per month was the highest in January, with an average of 469 cases, and was the lowest in September, with an average of 291 cases, although most were diagnosed with KD in winter (29.3\%). Granger tests showed that PDR for HRSV, rotavirus, and norovirus were related with KD incidence by 1 month, while PDR for HRSV, HRV, rotavirus, and norovirus by 2 months. This study found that detection rates of respiratory and enteric viruses preceded KD by 1-2 months. Further research is needed to confirm the association between these viruses and KD.
\end{abstract}

Keywords: Kawasaki disease; virus; children

\section{Introduction}

Kawasaki disease (KD) is a systemic vasculitis that occurs mainly in children under 5 years of age, and is often accompanied by coronary artery lesions. It was first described by Tomisaku Kawasaki in 1967, and is now the most common cause of acquired heart disease in children in developed countries [1]. For KD diagnosis, a fever lasting more than 5 days, with findings of more than five characteristic clinical symptoms are required, in the setting where 
no other diagnosis could explain the results. The five characteristic clinical symptoms of KD are (1) bilateral conjunctival injection; (2) oral mucosal changes; (3) polymorphous skin rash; (4) peripheral extremity changes; and (5) cervical lymphadenopathy [2,3]. Incomplete KD may be considered in the presence of only one or two principal clinical features after very careful, sufficient observation, and excluding other diagnoses. Although the incidence rate varies among countries, Asian countries are expected to have a higher KD incidence than most Western countries [4].

The cause of KD has yet to be identified, but it is estimated to be caused by infectious diseases, such as viruses or hemolytic streptococcus, given that several studies have confirmed this association with common respiratory viruses. However, the role of respiratory viruses in KD pathogenesis remains unknown, and studies on this association with various viruses other than respiratory viruses are insufficient $[5,6]$.

Thus, we aimed to analyze public health data provided by the Health Insurance Review and Assessment (HIRA) Open Access Big Data Platform and Korea Disease Control and Prevention Agency (KDCA) to determine the relationship between respiratory and gastrointestinal viruses and KD incidence.

\section{Materials and Methods}

\subsection{Study Population}

We extracted data regarding KD from the HIRA, which is a government-affiliated organization created to build an accurate claims review and quality assessment system for the National Health Insurance, with databases open for all academic investigators [7-9]. Claims data in the HIRA database include patient diagnosis, treatment, procedures, surgical history, and prescription drugs, serving as a valuable resource for healthcare service research. We studied the HIRA data of KD patients who received IVIG treatment (ICD10, M30.3), including a total of 16,740 incident KD cases between 1 January 2015, and 31 December 2018 (Figure 1). Most patients were under 18 years of age, with only two patients older than 18 years. Thus, only $16,738 \mathrm{KD}$ patients were analyzed, excluding the two patients aged $>18$ years.

All cases with diagnosis code for Kawasaki disease (M30.3) from 1 January 2015 to 31 December 2018

Patients who received the IVIG treatment during hospitalization

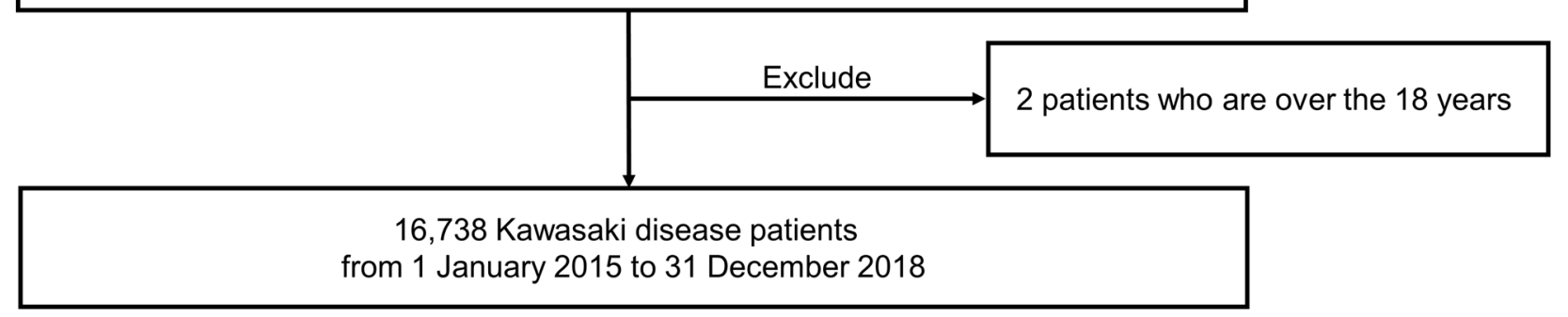

Figure 1. Flowchart illustrating patient selection. 


\subsection{The Surveillance Data of Virus}

We used the data reported by the KDCA on viruses that cause acute respiratory infections and gastroenteritis, wherein more than 4000 respiratory and 2000 enteric specimens were collected from 17 local environmental and health institutes, and over 100 participating hospitals across Korea during each year of the study period. The causative pathogens were then identified using standardized diagnostic procedures in a central laboratory, in which pathogen prevalence was surveyed weekly, and was analyzed based on genetic testing of influenza-like illness or acute diarrhea patients. The positive detection rate (PDR) data was then collected during the study period from 2015 to 2018, calculating the average monthly PDRs of seven respiratory viruses (adenovirus (HAdV), parainfluenza virus (HPIV), respiratory syncytial virus (HRSV), influenza virus (IFV), coronavirus (HCoV), rhinovirus (HRV), and bocavirus $(\mathrm{HBoV})$ ) and four acute diarrhea viruses (adenovirus, rotavirus, norovirus, and astrovirus).

\subsection{Statistical Analyses}

For incidence rate calculations, we used the 2015 Korean population data edited by the Ministry of the Interior and Safety as the denominator, with a total of 8,961,805 people under the age of 18 years. We then constructed a model of variations in ITP diagnosis, using the autoregressive integrated moving average (ARIMA) modeling approach, which assumes that the current observation is related to past observations over time. The general multiplicative form of the ARIMA model was denoted as (p, $d, q)$, wherein $p, d$, and $q$ were the order values of non-seasonal, autoregressive, differencing, and moving average parameters, respectively. Additionally, the autocorrelation function (ACF) was examined to identify the general form of the model to be fit. Considering the ACF graphs, different ARIMA models were identified for model selection (Supplemental Figure S1), and the minimum Akaike's information criterion model was chosen as the best-fit model (Supplemental Table S1). Moreover, the Granger approach was used to investigate how many of the current values in the time series y could be described as other values [10]. The data were analyzed using the R software, and significance was defined as $p<0.05$ for all analyses.

\section{Results}

\subsection{Patient Characteristics}

During the 4-year-period, 16,740 patients were diagnosed with KD (Table 1). Of these, $15,635(93.4 \%)$ patients were under 5 years of age, $6993(41.8 \%)$ were aged $0-1$ years, 8642 $(51 \%)$ were aged $1.1-5$ years, $1103(6.6 \%)$ were aged $5.1-18$ years, and only $2(0.0 \%)$ were over 18 years of age. Regarding sex, there were 9631 male and 7109 female patients in the study. The KD incidence rate for patients under 18 years of age was $46.7 / 100,000$ person-years (Table 2). Based on age group, the incidence rates were 172.4, 411.8, 117.3, and 4.1 in $0-5$ years, $0-1$ years, $1.1-5$ years, and $5.1-18$ years, respectively.

\subsection{Trend Analysis of KD}

Of the 16,738 patients under 18 years of age, 5870 were diagnosed in 2015, 3922 in 2016, 3111 in 2017, and 3835 in 2018. The highest incidence rate in 2015-2016 was in January, and in 2017-2018, it was highest in December (Table 3). Overall, the cumulative cases per month for four years were found to be the highest in January and the lowest in September (Figure 2A,B). Additionally, KD patients were most often diagnosed during winter (29.4\%), followed by spring $(25.0 \%)$, summer $(23.1 \%)$, and then autumn $(22.6 \%)$ (Figure $2 \mathrm{C})$. The average number of cases per month was 348.7, and the average number of cases per year between 2015 and 2018 was 4184.5. 
Table 1. Characteristics of patients.

\begin{tabular}{|c|c|c|}
\hline Variables & & $n(\%)$ \\
\hline Total number of patients & & $16,740(100.0)$ \\
\hline \multicolumn{3}{|l|}{ Age group } \\
\hline & $0-5$ years & $15,635(93.4)$ \\
\hline & $0-1$ years & $6993(41.8)$ \\
\hline & $1.1-5$ years & $8642(51.6)$ \\
\hline & $5.1-18$ years & $1103(6.6)$ \\
\hline & $>18$ years & $2(0.0)$ \\
\hline \multicolumn{3}{|l|}{ Sex } \\
\hline & Male & $9631(57.5)$ \\
\hline & Female & $7109(42.5)$ \\
\hline \multicolumn{3}{|l|}{ Location } \\
\hline & Seoul & $3874(23.1)$ \\
\hline & Busan & $834(5.0)$ \\
\hline & Daegu & $1206(7.2)$ \\
\hline & Incheon & $1196(7.1)$ \\
\hline & Gwangju & $536(3.2)$ \\
\hline & Daejeon & $822(4.9)$ \\
\hline & Ulsan & $361(2.2)$ \\
\hline & other & $7911(47.4)$ \\
\hline \multicolumn{3}{|l|}{ Insurance type } \\
\hline & Medical insurance & $16,623(99.3)$ \\
\hline & Medical aid & $117(0.7)$ \\
\hline & Other & \\
\hline
\end{tabular}

Table 2. Characteristics of patients under 18 years of age.

\begin{tabular}{cccccc}
\hline Age Group (Years) & $\begin{array}{c}\text { Number of } \\
\text { Patients, } \boldsymbol{n}(\mathbf{\%})\end{array}$ & Male, $\boldsymbol{n} \mathbf{( \% )}$ & Female, $\boldsymbol{n} \mathbf{( \% )}$ & M:F Ratio * & Incidence Rate ** \\
\hline $0.1-5$ & $15,635(93.4)$ & $9009(53.5)$ & $6626(39.3)$ & 1.36 & 172.4 \\
$0.1-1$ & $6993(41.8)$ & $4197(25.0)$ & $2796(16.6)$ & 1.5 & 411.8 \\
$1.1-5$ & $8642(51.6)$ & $4812(28.6)$ & $3830(22.7)$ & 1.26 & 117.3 \\
$5.1-18$ & $1103(6.6)$ & $621(3.7)$ & $482(2.9)$ & 1.29 & 4.1 \\
Total & $16,738(100.0)$ & $9630(57.5)$ & $7108(42.5)$ & 1.35 & 46.7 \\
\hline
\end{tabular}

* M:F ratio $=$ male-to-female ratio. ${ }^{* *}$ Incidence rate per 100,000 population.

Table 3. Monthly numbers of newly diagnosed pediatric Kawasaki disease patients in Korea.

\begin{tabular}{ccccccccccccccc}
\hline & January & February & March & April & May & June & July & August & September & October & November & December & Total & Average \\
\hline 2015 & 663 & 481 & 526 & 480 & 551 & 511 & 422 & 415 & 383 & 421 & 481 & 536 & 5870 & 489.2 \\
2016 & 596 & 393 & 355 & 317 & 342 & 343 & 265 & 261 & 236 & 205 & 257 & 352 & 3922 & 326.8 \\
2017 & 303 & 248 & 251 & 219 & 305 & 244 & 258 & 216 & 246 & 250 & 233 & 338 & 3111 & 259.3 \\
2018 & 313 & 220 & 268 & 231 & 334 & 340 & 279 & 315 & 297 & 331 & 435 & 472 & 3835 & 319.6 \\
Total & 1875 & 1342 & 1400 & 1247 & 1532 & 1438 & 1224 & 1207 & 1162 & 1207 & 1406 & 1698 & 16,738 & 1394.8 \\
Average & 468.8 & 335.5 & 350.0 & 311.8 & 383.0 & 359.5 & 306.0 & 301.8 & 290.5 & 301.8 & 351.5 & 424.5 & 4184.5 & 348.7 \\
\hline
\end{tabular}




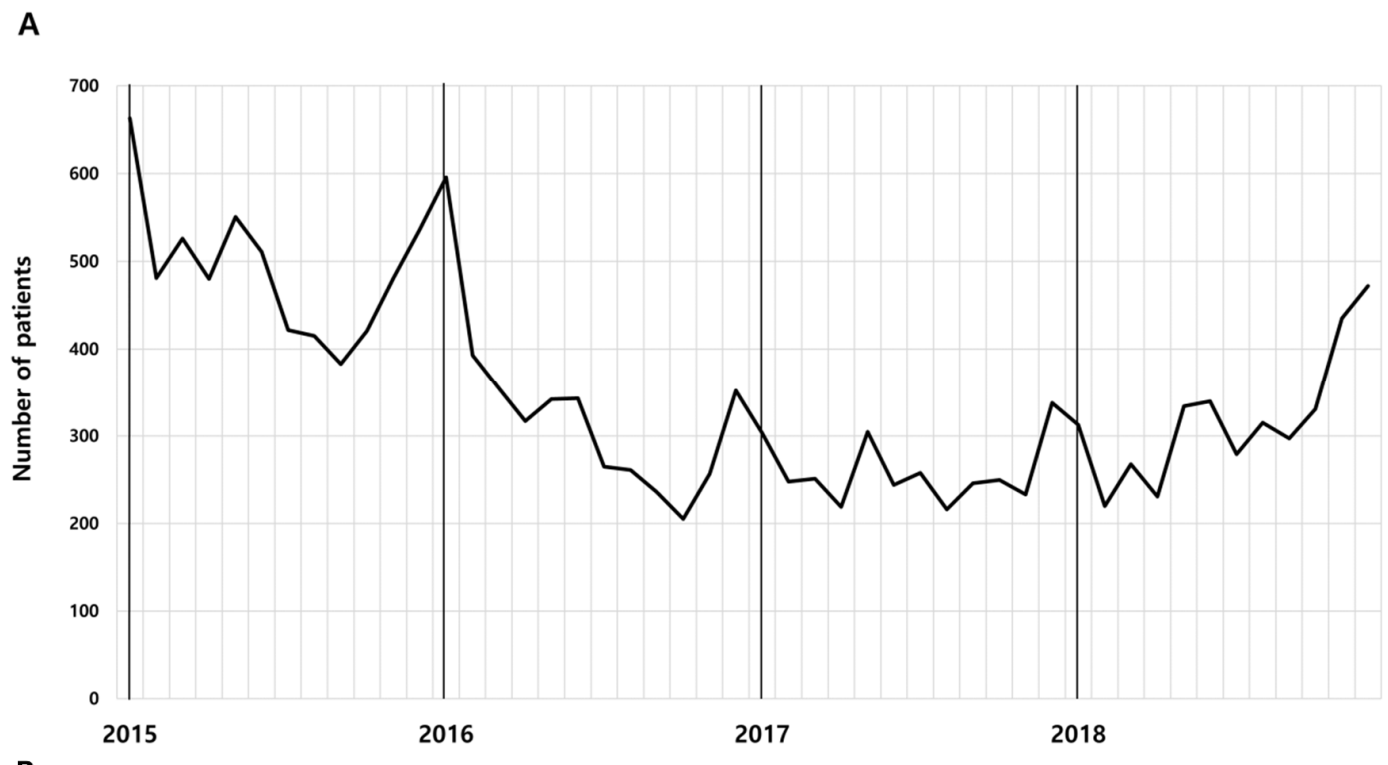

B
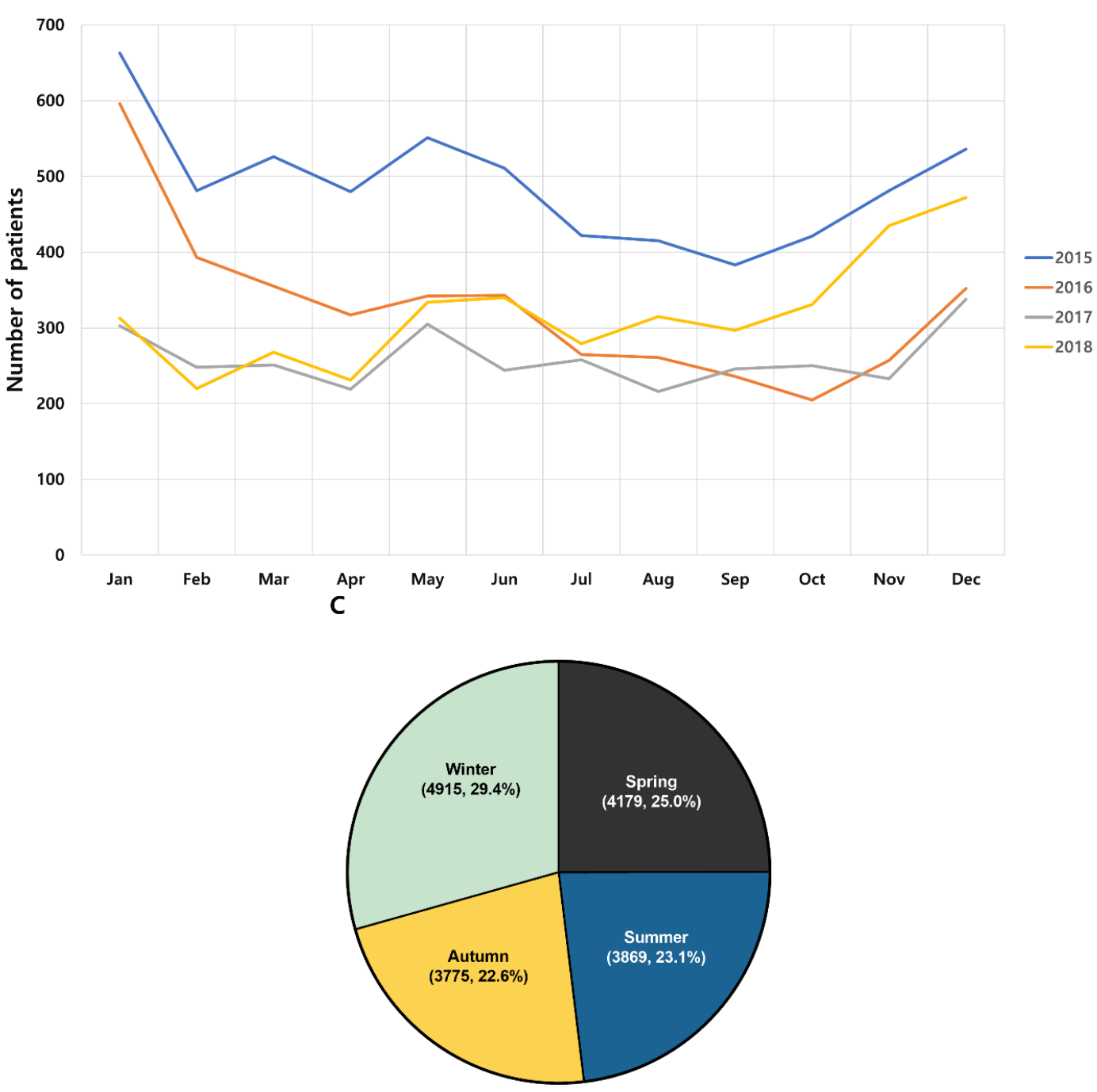

Figure 2. Incidence trend of Kawasaki disease from 2015 to 2018. (A) Monthly trend analysis Kawasaki disease from 2015 to 2018. (B) Monthly trend analysis of Kawasaki disease according to year. (C) Seasonal trend Kawasaki disease incidence. Spring (March to May), summer (June to August), autumn (September to November) and winter (December to February). (Cumulative incidence for 4 years, \%). 


\subsection{Positive Detection Rates of Virus}

The PDRs of most viruses showed seasonal variations (Supplemental Table S2). Specifically, HAdV was highest in November, HPIV was highest in May, and HRSV was especially high in winter, with the highest number of HRSV cases in November. Furthermore, IFV was highest from November to February, and $\mathrm{HCoV}$ and norovirus were the highest from November to January. HRV and enteric HAdV were highest in September; HBoV was highest from May to June; and HMPV, rotavirus, and astrovirus were the highest in April, March, and January, respectively. The PDR of all viruses was highest in December, and lowest in July.

\subsection{Causality between KD and Virus Prevalence}

If any prevalent virus affected KD diagnosis, the prevalence of that virus might increase before the peak of KD diagnosis. Thus, a Granger causality test was conducted between the virus PDR and KD diagnostic data collected 1 to 2 months later. The results of this test are shown in Table 4. Among the seven respiratory and four gastrointestinal viruses, the prevalence of certain viruses increased 1-2 months before the KD incidence increased. The PDRs for HRSV $(p<0.001)$, rotavirus $(p=0.048)$, and norovirus $(p<0.001)$ in patients aged $<5$ years correlated with increased KD incidence after 1 month (Table $4 \mathrm{~A}$ ); however, there was no statistical correlation between KD incidence and patients aged $5-18$ years, and rotavirus was not statistically correlated at $1-5$ years of age. Moreover, the PDRs for HRSV $(p<0.001)$, HRV $(p=0.001)$, rotavirus $(p=0.032)$, and norovirus $(p<0.001)$ in patients aged $<5$ years correlated with increased KD incidence after 2 months (Table 4B). There was no statistical correlation between KD incidence and patients aged 5-18 years, and rotavirus was also not statistically correlated at $1-5$ years of age. Figure 3 shows the relationship between the PDRs of HRSV, HRV, norovirus, rotavirus, and KD incidence during the study period.

Table 4. Values of the Granger causality test between the time series of Kawasaki disease diagnosis and the time points of positive detection rates of virus, with $<0.05$ indicating significance (written in bold).

\begin{tabular}{|c|c|c|c|c|c|c|c|c|c|c|c|c|}
\hline \multicolumn{13}{|c|}{ A. Diagnostic Data and Virus Data after 1 Month } \\
\hline $\begin{array}{l}\text { Age } \\
\text { Group } \\
\text { (Years) }\end{array}$ & HAdV & HPIV & HRSV & IFV & $\mathrm{HCoV}$ & HRV & HBoV & HMPV & Rotavirus & Norovirus & Adenovirus & Astrovirus \\
\hline$<5$ & 0.720 & 0.495 & $<0.001$ & 0.271 & 0.221 & 0.279 & 0.478 & 0.236 & 0.048 & $<0.001$ & 0.505 & 0.586 \\
\hline $0-1$ & 0.756 & 0.593 & $<0.001$ & 0.216 & 0.102 & 0.672 & 0.644 & 0.850 & 0.014 & $<0.001$ & 0.519 & 0.459 \\
\hline $1.1-5$ & 0.552 & 0.392 & $<0.001$ & 0.516 & 0.403 & 0.259 & 0.298 & 0.059 & 0.256 & 0.007 & 0.612 & 0.887 \\
\hline $5.1-18$ & 0.970 & 0.532 & 0.210 & 0.661 & 0.389 & 0.220 & 0.476 & 0.567 & 0.590 & 0.290 & 0.636 & 0.783 \\
\hline Total & 0.721 & 0.487 & $<0.001$ & 0.337 & 0.289 & 0.256 & 0.438 & 0.294 & 0.053 & $<0.001$ & 0.432 & 0.662 \\
\hline \multicolumn{13}{|c|}{ B. Diagnostic Data and Virus Data after 2 Months } \\
\hline $\begin{array}{l}\text { Age } \\
\text { Group } \\
\text { (Years) }\end{array}$ & HAdV & HPIV & HRSV & IFV & $\mathrm{HCoV}$ & HRV & HBoV & HMPV & Rotavirus & Norovirus & Adenovirus & Astrovirus \\
\hline$<5$ & 0.129 & 0.603 & $<0.001$ & 0.368 & 0.190 & 0.001 & 0.448 & 0.541 & 0.032 & $<0.001$ & 0.668 & 0.859 \\
\hline $0-1$ & 0.181 & 0.936 & $<0.001$ & 0.340 & 0.138 & 0.031 & 0.871 & 0.991 & 0.046 & $<0.001$ & 0.448 & 0.764 \\
\hline $1.1-5$ & 0.145 & 0.352 & 0.030 & 0.659 & 0.374 & 0.002 & 0.219 & 0.185 & 0.076 & 0.017 & 0.911 & 0.993 \\
\hline $5.1-18$ & 0.657 & 0.812 & 0.111 & 0.717 & 0.194 & 0.307 & 0.155 & 0.661 & 0.165 & 0.243 & 0.096 & 0.625 \\
\hline Total & 0.151 & 0.591 & $<0.001$ & 0.426 & 0.183 & 0.002 & 0.382 & 0.594 & 0.028 & $<0.001$ & 0.636 & 0.916 \\
\hline
\end{tabular}

HAdV, human adenovirus; HPIV, human parainfluenza virus; HRSV, human respiratory syncytial virus; IFV, influenza virus; HCoV, human coronavirus; $\mathrm{HRV}$, human rhinovirus; $\mathrm{HBOV}$, human bocavirus; $\mathrm{HMPV}$, human metapneumovirus. 

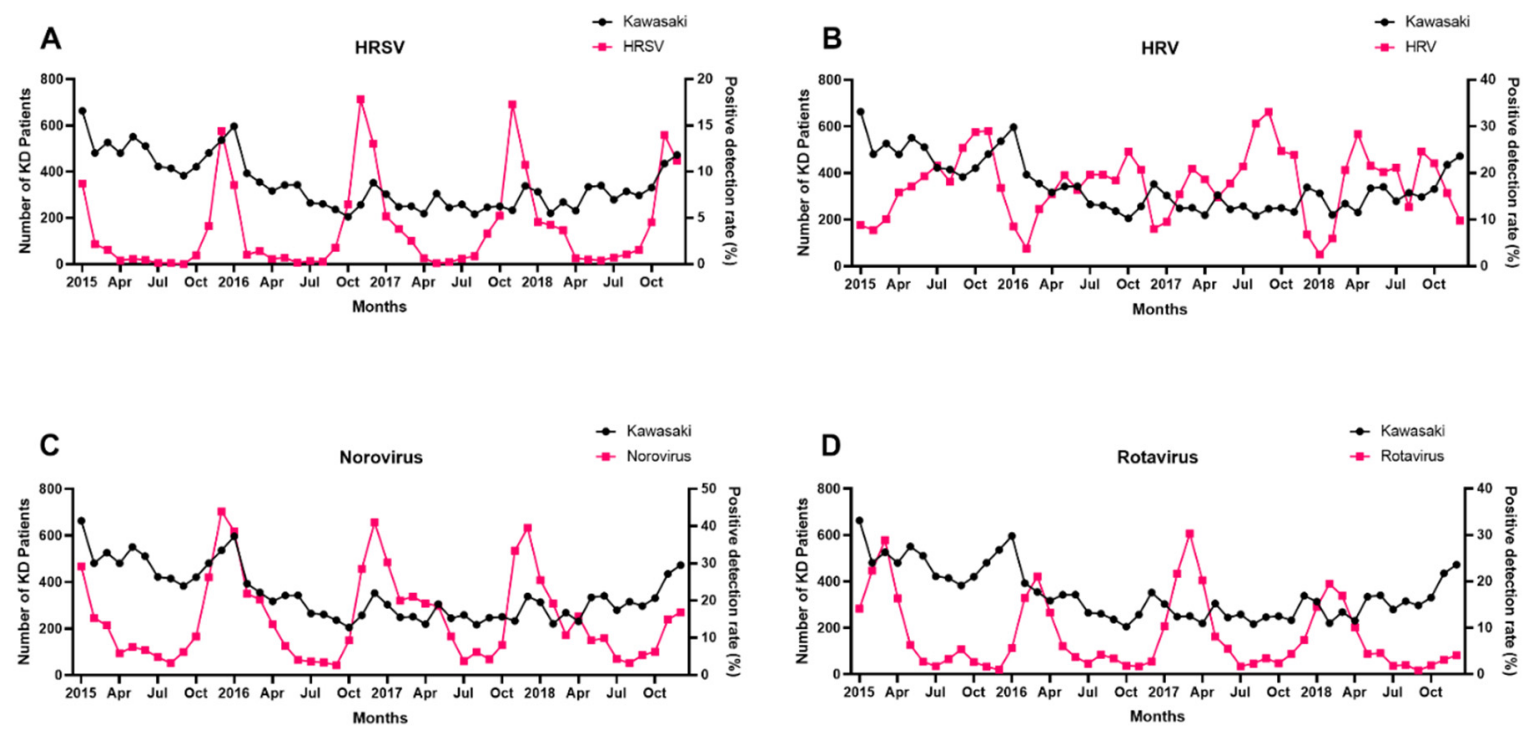

Figure 3. Relationship between PDR of (A) HRSV, (B) HRV, (C) norovirus, (D) rotavirus and incidence of KD during the study period.

\section{Discussion}

This study evaluated the incidence of KD and its association with viral infections. We found that certain respiratory and gastroenteritis viral PDR were significantly associated with KD incidence after 1 and 2 months.

The KD incidence in Northeast Asian countries, such as South Korea, Japan, China, and Taiwan, is 10-30 times higher as compared to Western countries, such as the United States and Europe [11-13]. In a 2014 Japanese nationwide study, the number of KD patients was reported to be 15,979 , resulting in an annual incidence rate of 308.0 per 100,000 children aged $0-4$ years, with a M/F ratio of 1.32 . This was the highest recorded KD incidence in Japan [12]. In a previous Korean study analyzed using the HIRA database, a total of 39,082 patients was reported between 2007 and 2014 [14]. The M/F ratio was 1.42, and the median age was 28 months. The incidence rates were 210.4 per 100,000 children aged 0 to 4 years in 2013 and 217.2 in 2014.

In this study, KD incidence based on age and sex was similar to the previous Korean study. A total of 16,740 KD patients were diagnosed between 2015 and 2018, with a M/F ratio of 1.36 and a median age of 30 months. Of these, $93.4 \%$ were under 5 years of age, and $41.8 \%$ were aged $0-1$ years. The incidence rate was $172.4 / 100,000$ children under 5 years of age, 411.8 in $0-1$ years, and 117.3 in $1-5$ years of age.

It is generally established that KD may be triggered by an infectious agent which activates the immune system in a genetically susceptible host $[4,15,16]$. As a basis for this, seasonal clustering in winter and spring is similarly seen in other viral diseases. Furthermore, temporal clusters of epidemics have already been reported in several countries [13].

Although KD had temporal clustering, different seasonality was found in different countries. In this study, the prevalence of KD in Korea was high in spring and winter, as in previous studies [14]. In Europe, the prevalence is high in winter, and in China, the prevalence is high in spring and summer $[17,18]$. In Japan, the prevalence is high in January and summer [19]. No single pathogen associated with KD has been reported worldwide. Chang et al. argued that it is not the same infectious etiology that causes KD, but is a heterogeneous source of infection according to regions and seasons [4].

$\mathrm{KD}$ is most common in children between 6 months and 5 years of age, making them the most susceptible to infections, before improving 1-3 weeks after onset [20]. In the Japanese nationwide survey, KD showed a peak incidence in January and February in winter [21], which is similar to our study given that Korean KD also occurred most frequently in winter $(29.4 \%)$. 
Many attempts have also been made to elucidate the association between viruses (adenovirus, rhinovirus, bocavirus, coronavirus, $\mathrm{CMV}, \mathrm{EBV}$, herpes, poliovirus, rotavirus) and KD, and while some have obtained meaningful data, no clear answer has yet been obtained [4,22-26].

In this study, we found that the HRV and HRSV prevalence among other respiratory viruses and KD incidence were statistically correlated.

Notably, HRV is relatively recent, making its association with KD more probable. Chang et al. conducted a prospective case-control study on $226 \mathrm{KD}$ children and confirmed the association between various viruses, including HRV and KD [4]. Additionally, Turnier et al. retrospectively analyzed 192 KD patients, wherein $41.9 \%$ of the patients tested positive for respiratory virus PCR, with most of them positive for rhinovirus/enterovirus [5]. Moreover, L'Huillier et al. confirmed KD pediatric blood using high-throughput sequencing. As a result, it was reported that there was a temporal association with KD using vaccine records, such as polio and measles, hinting possible associations with rhinovirus and bocavirus [27]. These studies are consistent with our findings and can be considered as a reinforcement of our results.

Regarding HRSV, its association with KD appears to be low, given the lacking evidence in several studies attempting to establish an association with KD in all respiratory viruses [23]. In fact, only one case of co-infection of HRSV and HMPV in a 24-month-old child with KD was reported [28]. This is the first study to check the association between HRSV and KD using national health big data.

In comparison, many studies have investigated the association between HAdV and $\mathrm{KD}$ [22,29-32]. Song et al. reported that the adenovirus is very common and is similar to $\mathrm{KD}$ in that it has the highest disease incidence in children under 5 years of age. In addition, the majority of children with adenovirus had clinical characteristics similar to those of KD in that study. Based on this, they were able to accidentally detect adenovirus in KD patients; thus, KD diagnosis cannot be completely excluded when an adenovirus is detected [22]. In our study, there was no significant difference between adenovirus prevalence and KD incidence under 18 years of age, which may be related to the limitations of our study.

Compared to respiratory viruses, few studies have been conducted on the association between gastrointestinal viruses and $\mathrm{KD}$, showing an association between $\mathrm{KD}$ and rotavirus infection. A study by Matsuno et al. presented evidence of rotavirus infection in KD patients, wherein 39 samples were obtained from hospitalized KD patients, and rotavirus capsomer aggregates were found in 26 of them [26]. Mellone et al. also reported that monovalent and pentavalent rotavirus vaccines lowered KD incidence [33], although some cases have reported KD following rotavirus vaccination [34]. In addition, a cohort study using commercial insurance data investigated the side effects associated with the rotavirus vaccine, showing that 23 cases were diagnosed with KD out of a total 2,468,002 concomitant diphtheria-tetanus-pertussis vaccinations among children [35].

In this study, the rotavirus was statistically associated for children under the age of 1 year; however, no association was found for children aged 1-5 years, suggesting that extensive rotavirus vaccination may have affected the results. The rotavirus vaccine in South Korea is a 2- or 3-dose schedule indicated for infants aged 6-32 weeks (i.e., at 2 and 4 months, or at 2, 4, and 6 months) [36]. Moreover, rotavirus antibodies are detected in the blood serum within 2 days after diarrhea onset [37]. In that regard, it is assumed that the antibody formation of rotavirus may have influenced KD incidence.

In our current study, the PDR of norovirus was also found to be related to KD incidence. One case reported that secondary infections, such as norovirus infection, can worsen systemic vasculitis, such as Henoch-Schonlein purpura [38]. However, it is not yet known how norovirus infection affects KD development. Research on this topic is needed in future studies.

Despite these findings, this study had certain limitations. First, this was a retrospective study, which has a lower evidence level when compared to prospective studies and may have had selection bias. Second, as a limitation of data, the information collected from 
HIRA did not include the clinical content of the patients. Moreover, patients who had been tested for viral infection were different from those who had been diagnosed with KD. Therefore, it was not possible to establish a direct relationship between viral infection and $\mathrm{KD}$, since only the predecessor relationship could be assessed through the incidence rate. However, the trend of incidence with virus detection rate in KD was represented by a time series graph and was analyzed using the Granger causality test. The association between the number of KD patients and viral transmission cannot be definitively concluded. Since viral infections are common in winter, much more epidemiological data is needed to link viral epidemics to the onset of Kawasaki disease.

\section{Conclusions}

This study evaluated KD incidence and investigated its correlation with the prevalence of common viral respiratory and gastrointestinal infections. To our knowledge, and to date, this is the largest nationwide analysis of patients with KD and their association with the PDRs of common viruses in Korea. In Korea, infection rates by HRSV, rotavirus, norovirus, and HRV were found to precede the incidence of KD by 1-2 months. Thus, it is possible that these viruses acted as triggers for KD development. Prospective studies on these respiratory and gastrointestinal viruses and KD are needed in the future to further elucidate these associations.

Supplementary Materials: The following are available online at https:/ /www.mdpi.com/article/10 .3390/jcm10153301/s1, Table S1: Parameters of ARIMA models for Kawasaki disease patients by age, Table S2: Positive detection rates of virus during study period, Figure S1: Residual ACF correlogram and $95 \%$ confidence limits for newly diagnosed Kawasaki disease.

Author Contributions: Y.K.K., S.H.M. and J.H.L. contributed to the conception, design, and data collection. S.W.K. contributed to the assembly of data, data analysis, and interpretation. Y.H.L. and J.M.L. contributed to the conception, design, and interpretation. All authors have read and agreed to the published version of the manuscript.

Funding: This research received no external funding.

Institutional Review Board Statement: This study was approved by the Institutional Review Board of the Yeungnam University Medical Center (IRB No: YUMC 2020-05-099).

Informed Consent Statement: All procedures performed in studies involving human participants were in accordance with the ethical standards of the institutional and/or national research committee and with the 1964 Helsinki declaration and its later amendments or comparable ethical standards. For this type of study, formal consent is not required.

Data Availability Statement: The data presented in this study are available on request from the corresponding author.

Conflicts of Interest: The authors declare no conflict of interest.

\section{References}

1. Kawasaki, T.; Singh, S. Kawasaki disease-The journey over 50 years: 1967-2017. Int. J. Rheum. Dis. 2018, 21, 7-9. [CrossRef]

2. Kobayashi, T.; Ayusawa, M.; Suzuki, H.; Abe, J.; Ito, S.; Kato, T.; Kamada, M.; Shiono, J.; Suda, K.; Tsuchiya, K.; et al. Revision of diagnostic guidelines for Kawasaki disease (6th revised edition). Pediatr. Int. 2020, 62, 1135-1138. [CrossRef] [PubMed]

3. Ae, R.; Makino, N.; Kosami, K.; Kuwabara, M.; Matsubara, Y.; Nakamura, Y. Epidemiology, Treatments, and Cardiac Complications in Patients with Kawasaki Disease: The Nationwide Survey in Japan, 2017-2018. J. Pediatr. 2020, 225, 23-29.e2. [CrossRef] [PubMed]

4. Chang, L.Y.; Lu, C.Y.; Shao, P.L.; Lee, P.I.; Lin, M.T.; Fan, T.Y.; Cheng, A.L.; Lee, W.L.; Hu, J.J.; Yeh, S.J.; et al. Viral infections associated with Kawasaki disease. J. Formos. Med. Assoc. 2014, 113, 148-154. [CrossRef]

5. Jordan-Villegas, A.; Chang, M.L.; Ramilo, O.; Mejías, A. Concomitant respiratory viral infections in children with Kawasaki disease. Pediatr. Infect. Dis. J. 2010, 29, 770-772. [CrossRef]

6. Turnier, J.L.; Anderson, M.S.; Heizer, H.R.; Jone, P.N.; Glode, M.P.; Dominguez, S.R. Concurrent Respiratory Viruses and Kawasaki Disease. Pediatrics 2015, 136, e609-e614. [CrossRef]

7. Kim, L.; Kim, J.A.; Kim, S. A guide for the utilization of Health Insurance Review and Assessment Service National Patient Samples. Epidemiol. Health 2014, 36, e2014008. [CrossRef] 
8. Kim, D.S. Introduction: Health of the health care system in Korea. Soc. Work Public Health 2010, 25, 127-141. [CrossRef] [PubMed]

9. Kim, D.S. Special issue on the national health care system of South Korea. Soc. Work Public Health 2010, 25, 125-126. [CrossRef]

10. Granger, C.W.J. Investigating Causal Relations by Econometric Models and Cross-spectral Methods. Econometrica 1969, $37,424$. [CrossRef]

11. Kim, G.B. Reality of Kawasaki disease epidemiology. Korean J. Pediatr. 2019, 62, 292-296. [CrossRef] [PubMed]

12. Makino, N.; Nakamura, Y.; Yashiro, M.; Sano, T.; Ae, R.; Kosami, K.; Kojo, T.; Aoyama, Y.; Kotani, K.; Yanagawa, H. Epidemiological observations of Kawasaki disease in Japan, 2013-2014. Pediatr. Int. Off. J. Jpn. Pediatr. Soc. 2018, 60, 581-587. [CrossRef]

13. Uehara, R.; Belay, E.D. Epidemiology of Kawasaki Disease in Asia, Europe, and the United States. J. Epidemiol. 2012, 22, 79-85. [CrossRef] [PubMed]

14. Ha, S.; Seo, G.H.; Kim, K.Y.; Kim, D.S. Epidemiologic Study on Kawasaki Disease in Korea, 2007-2014: Based on Health Insurance Review \& Assessment Service Claims. J. Korean Med. Sci. 2016, 31, 1445-1449. [CrossRef] [PubMed]

15. Agarwal, S.; Agrawal, D.K. Kawasaki disease: Etiopathogenesis and novel treatment strategies. Expert Rev. Clin. Immunol. 2017, 13, 247-258. [CrossRef] [PubMed]

16. Dimitriades, V.R.; Brown, A.G.; Gedalia, A. Kawasaki Disease: Pathophysiology, Clinical Manifestations, and Management. Curr. Rheumatol. Rep. 2014, 16, 423. [CrossRef]

17. Du, Z.D.; Zhao, D.; Du, J.; Zhang, Y.L.; Lin, Y.; Liu, C.; Zhang, T. Epidemiologic study on Kawasaki disease in Beijing from 2000 through 2004. Pediatr. Infect. Dis. J. 2007, 26, 449-451. [CrossRef] [PubMed]

18. Lynch, M.; Holman, R.C.; Mulligan, A.; Belay, E.D.; Schonberger, L.B. Kawasaki syndrome hospitalizations in Ireland, 1996 through 2000. Pediatr. Infect. Dis. J. 2003, 22, 959-963. [CrossRef]

19. Burns, J.C.; Cayan, D.R.; Tong, G.; Bainto, E.V.; Turner, C.L.; Shike, H.; Kawasaki, T.; Nakamura, Y.; Yashiro, M.; Yanagawa, H. Seasonality and Temporal Clustering of Kawasaki Syndrome. Epidemiology 2005, 16, 220-225. [CrossRef]

20. Galeotti, C.; Bayry, J.; Kone-Paut, I.; Kaveri, S.V. Kawasaki disease: Aetiopathogenesis and therapeutic utility of intravenous immunoglobulin. Autoimmun. Rev. 2010, 9, 441-448. [CrossRef]

21. Ozeki, Y.; Yamada, F.; Saito, A.; Kishimoto, T.; Yashiro, M.; Makino, N.; Nakamura, Y. Epidemiologic features of Kawasaki disease distinguished by seasonal variation: An age-specific analysis. Ann. Epidemiol. 2018, 28, 796-800. [CrossRef]

22. Song, E.; Kajon, A.E.; Wang, H.; Salamon, D.; Texter, K.; Ramilo, O.; Leber, A.; Jaggi, P. Clinical and Virologic Characteristics May Aid Distinction of Acute Adenovirus Disease from Kawasaki Disease with Incidental Adenovirus Detection. J. Pediatr. 2016, 170, 325-330. [CrossRef]

23. Kim, J.H.; Yu, J.J.; Lee, J.; Kim, M.N.; Ko, H.K.; Choi, H.S.; Kim, Y.H.; Ko, J.K. Detection rate and clinical impact of respiratory viruses in children with Kawasaki disease. Korean J. Pediatr. 2012, 55, 470-473. [CrossRef]

24. Esper, F.; Shapiro, E.D.; Weibel, C.; Ferguson, D.; Landry, M.L.; Kahn, J.S. Association between a novel human coronavirus and Kawasaki disease. J. Infect. Dis. 2005, 191, 499-502. [CrossRef] [PubMed]

25. Catalano-Pons, C.; Quartier, P.; Leruez-Ville, M.; Kaguelidou, F.; Gendrel, D.; Lenoir, G.; Casanova, J.L.; Bonnet, D. Primary cytomegalovirus infection, atypical Kawasaki disease, and coronary aneurysms in 2 infants. Clin. Infect. Dis. Off. Publ. Infect. Dis. Soc. Am. 2005, 41, e53-e56. [CrossRef] [PubMed]

26. Matsuno, S.; Utagawa, E.; Sugiura, A. Association of rotavirus infection with Kawasaki syndrome. J. Infect. Dis. 1983, $148,177$. [CrossRef] [PubMed]

27. L'Huillier, A.G.; Brito, F.; Wagner, N.; Cordey, S.; Zdobnov, E.; Posfay-Barbe, K.M.; Kaiser, L. Identification of Viral Signatures Using High-Throughput Sequencing on Blood of Patients with Kawasaki Disease. Front. Pediatr. 2019, 7, 524. [CrossRef]

28. Shatizadeh Malekshahi, S.; Mokhtari Azad, T.; Shahmahmoodi, S.; Yavarian, J.; Rezaei, F.; Naseri, M. First report of respiratory syncytial virus and human metapneumovirus co-infection in a 2-year-old Kawasaki patient in Iran. Iran. J. Public Health 2010, 39, 140-142.

29. Giray, T.; Bicer, S.; Kucuk, O.; Col, D.; Yalvac, Z.; Gurol, Y.; Yilmaz, G.; Sac, A.; Mogol, Y. Four cases with Kawasaki disease and viral infection: Aetiology or association. Infez. Med. 2016, 24, 340-344.

30. Shike, H.; Shimizu, C.; Kanegaye, J.T.; Foley, J.L.; Schnurr, D.P.; Wold, L.J.; Burns, J.C. Adenovirus, adeno-associated virus and Kawasaki disease. Pediatr. Infect. Dis. J. 2005, 24, 1011-1014. [CrossRef]

31. Okano, M.; Thiele, G.M.; Sakiyama, Y.; Matsumoto, S.; Purtilo, D.T. Adenovirus infection in patients with Kawasaki disease. J. Med. Virol. 1990, 32, 53-57. [CrossRef] [PubMed]

32. Embil, J.A.; McFarlane, E.S.; Murphy, D.M.; Krause, V.W.; Stewart, H.B. Adenovirus type 2 isolated from a patient with fatal Kawasaki disease. Can. Med. Assoc. J. 1985, 132, 1400.

33. Mellone, N.G.; Silva, M.T.; Paglia, M.D.G.; Lopes, L.C.; Barberato-Filho, S.; Del Fiol, F.S.; Bergamaschi, C.C. Kawasaki Disease and the Use of the Rotavirus Vaccine in Children: A Systematic Review and Meta-Analysis. Front. Pharmacol. 2019, $10,1075$. [CrossRef] [PubMed]

34. Chang, A.; Islam, S. Kawasaki disease and vasculitis associated with immunization. Pediatr. Int. Off. J. Jpn. Pediatr. Soc. 2018, 60, 613-617. [CrossRef] [PubMed]

35. Layton, J.B.; Butler, A.M.; Panozzo, C.A.; Brookhart, M.A. Rotavirus vaccination and short-term risk of adverse events in US infants. Paediatr. Perinat. Epidemiol. 2018, 32, 448-457. [CrossRef] 
36. Cho, H.; Lee, H.; Kim, D.S.; Kim, H.M.; Kim, J.H.; Kim, A.Y.; Kang, H.Y. Socioeconomic Impact of the Rotavirus Vaccine in Korea: Comparing the Epidemiologic and Economic Characteristics of Rotavirus Gastroenteritis before and after the Introduction of Vaccines. Pediatr. Infect. Dis. J. 2020, 39, 460-465. [CrossRef]

37. Blutt, S.E.; Matson, D.O.; Crawford, S.E.; Staat, M.A.; Azimi, P.; Bennett, B.L.; Piedra, P.A.; Conner, M.E. Rotavirus antigenemia in children is associated with viremia. PLoS Med. 2007, 4, e121. [CrossRef]

38. McLaughlin, S.K.; Lawrence, L.; Adler, J.; Mehta, H. Henoch-Schonlein Purpura-Associated Hemorrhagic Shock after Secondary Norovirus Infection. Cureus 2020, 12, e11653. [CrossRef] [PubMed] 